\title{
Spectroscopic study on deuterated benzenes. III. Vibronic structure and dynamics in the S[1] state.
}

\section{$\operatorname{AUTHOR}(\mathrm{S})$ :}

Kunishige, Sachi; Katori, Toshiharu; Kawabata, Megumi; Yamanaka, Takaya; Baba, Masaaki

\section{CITATION:}

Kunishige, Sachi ...[et al]. Spectroscopic study on deuterated benzenes. III. Vibronic structure and dynamics in the S[1] state.. The Journal of chemical physics 2015, 143(24): 244304.

\section{ISSUE DATE:}

2015-12-28

URL:

http://hdl.handle.net/2433/207683

\section{RIGHT:}

C 2015 AIP Publishing. This article may be downloaded for personal use only. Any other use requires prior permission of the author and AIP Publishing. The following article may be found at http://scitation.aip.org/content/aip/journal/jcp/143/24/10.1063/1.4937951. 


\section{AIP | The Journal of}

Spectroscopic study on deuterated benzenes. III. Vibronic structure and dynamics in the S1 state

Sachi Kunishige, Toshiharu Katori, Megumi Kawabata, Takaya Yamanaka, and Masaaki Baba

Citation: The Journal of Chemical Physics 143, 244304 (2015); doi: 10.1063/1.4937951

View online: http://dx.doi.org/10.1063/1.4937951

View Table of Contents: http://scitation.aip.org/content/aip/journal/jcp/143/24?ver=pdfcov

Published by the AIP Publishing

\section{Articles you may be interested in}

Jet spectroscopy of buckybowl: Electronic and vibrational structures in the S 0 and $S 1$ states of triphenylene and sumanene

J. Chem. Phys. 139, 044313 (2013); 10.1063/1.4816636

Vibrational and rotational structure and excited-state dynamics of pyrene

J. Chem. Phys. 131, 224318 (2009); 10.1063/1.3270136

Structure and excited-state dynamics of anthracene: Ultrahigh-resolution spectroscopy and theoretical calculation

J. Chem. Phys. 130, 134315 (2009); 10.1063/1.3104811

Electronic spectroscopy of jet-cooled H C P + : Molecular structure, phosphorus hyperfine structure, and Renner-Teller analysis

J. Chem. Phys. 127, 104312 (2007); 10.1063/1.2767264

Fluorescence excitation and single vibronic level emission spectroscopy of the $A^{\sim} A^{\prime \prime} 1 \leftarrow X A^{\prime} 1$ system of $\mathrm{CHCl}$

J. Chem. Phys. 124, 224314 (2006); 10.1063/1.2204916

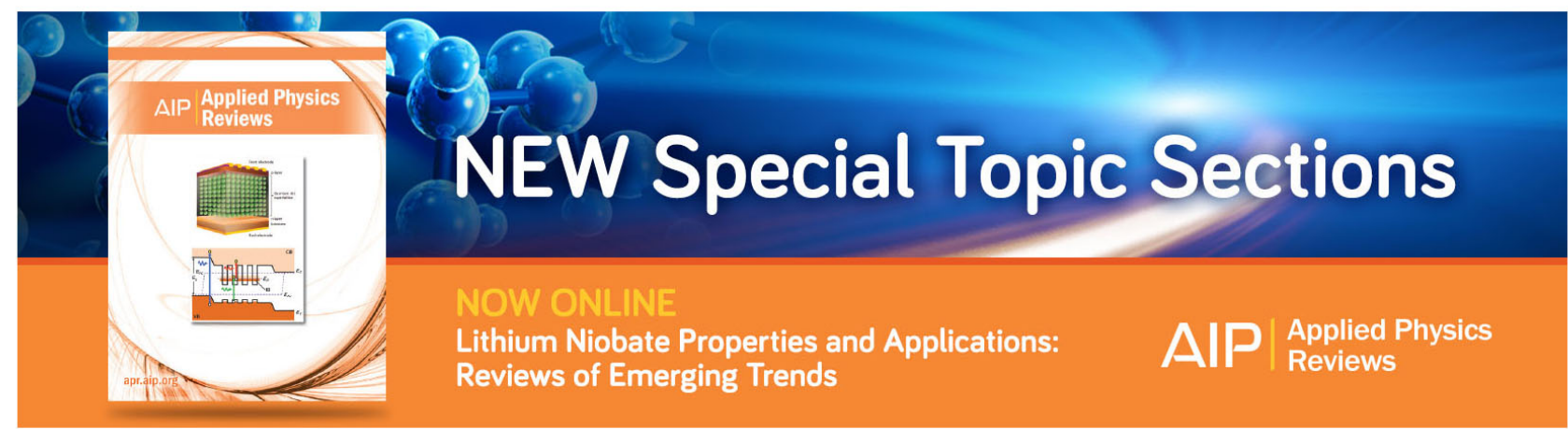




\title{
Spectroscopic study on deuterated benzenes. III. Vibronic structure and dynamics in the $S_{1}$ state
}

\author{
Sachi Kunishige, ${ }^{1}$ Toshiharu Katori, ${ }^{1}$ Megumi Kawabata, ${ }^{1}$ Takaya Yamanaka, ${ }^{2}$ \\ and Masaaki Baba ${ }^{1, a)}$ \\ ${ }^{1}$ Division of Chemistry, Graduate School of Science, Kyoto University, Kyoto 606-8502, Japan \\ ${ }^{2}$ Institute for Molecular Science, National Institute of Natural Science, Myodaiji, Okazaki 444-8585, Japan
}

(Received 14 September 2015; accepted 2 December 2015; published online 23 December 2015)

\begin{abstract}
We observed the fluorescence excitation spectra and mass-selected resonance enhanced multiphoton ionization (REMPI) excitation spectra for the $6_{0}^{1}, 6_{0}^{1} 1_{0}^{1}$, and $6_{0}^{1} 1_{0}^{2}$ bands of the $S_{1} \leftarrow S_{0}$ transition of jet-cooled deuterated benzene and assigned the vibronic bands of $\mathrm{C}_{6} \mathrm{D}_{6}$ and $\mathrm{C}_{6} \mathrm{HD}_{5}$. The $6_{0}^{1} 1_{0}^{n}$ $(n=0,1,2)$ and $0_{0}^{0}$ transition energies were found to be dependent only on the number of $\mathrm{D}$ atoms $\left(\mathrm{N}_{\mathrm{D}}\right)$, which was reflected by the zero-point energy of each $\mathrm{H} / \mathrm{D}$ isotopomer. In some isotopomers some bands, such as those of out-of-plane vibrations mixed with $6^{1} 1^{n}$, make the spectra complex. These included the $6^{1} 10^{2} 1^{n}$ level or combination bands with $v_{12}$ which are allowed because of reduced molecular symmetry. From the lifetime measurements of each vibronic band, some enhancement of the nonradiative intramolecular vibrational redistribution (IVR) process was observed. It was also found that the threshold excess energy of "channel three" was higher than the $6^{1} 1^{2}$ levels, which were similar for all the H/D isotopomers. We suggest that the channel three nonradiative process could be caused mainly by in-plane processes such as IVR and internal conversion at the high vibrational levels in the $S_{1}$ state of benzene, although the out-of-plane vibrations might contribute to some degree. (C) 2015 AIP Publishing LLC. [http://dx.doi.org/10.1063/1.4937951]
\end{abstract}

\section{INTRODUCTION}

The electronic excited states of benzene are of great interest and there have been extensive studies using molecular spectroscopy. ${ }^{1-9}$ The $\mathrm{C}_{6} \mathrm{H}_{6}$ molecule is a regular hexagon in the zero-vibrational level of the $S_{0}$ state, and the molecular structure has been found to be unchanged by deuterium substitution, as shown in Paper I. ${ }^{10}$ In the $S_{1}$ state, however, the molecular structure and potential energy surface are easily changed by various interactions among the electronic excited states. It is essential to accurately analyze the vibronic structure to elucidate the excited-state dynamics such as radiationless transition and photochemical reaction because these processes are controlled by the potential energy surface.

The $S_{1}{ }^{1} B_{2 u} \leftarrow S_{0}{ }^{1} A_{1 g}$ transition of benzene is forbidden and only the vibronic bands are observed in the excitation spectrum. The $6_{0}^{1}\left(v_{6}: e_{2 g}\right)$ band is strong, and its intensity arises from vibronic interaction between the $S_{1}{ }^{1} B_{2 u}$ and $S_{3}{ }^{1} E_{1 u}$ states. The $S_{3}{ }^{1} E_{1 u} \leftarrow S_{0}{ }^{1} A_{1 g}$ transition is allowed and the absorption band is very strong. In Paper III, we investigate the vibronic structure in the excitation spectra of the $S_{1} \leftarrow S_{0}$ transition of jet-cooled deuterated benzenes. The dominant bands are identified to be $6_{0}^{1}, 6_{0}^{1} 1_{0}^{1}$, and $6_{0}^{1} 1_{0}^{2}$, where $v_{1}$ is the totally symmetric $a_{1 g}$ mode called breathing. The $6_{0}^{1} 1_{0}^{3}$ band cannot be observed in the fluorescence excitation spectrum because the radiationless transition is drastically enhanced at the high vibrational level in the $S_{1}$ state. This is called "channel three." ${ }^{, 7}$ High-resolution spectroscopy showed that this was the combined channel of intramolecular vibrational redistribution

\footnotetext{
a) Author to whom correspondence should be addressed. Electronic mail: baba@kuchem.kyoto-u.ac.jp
}

(IVR) in the $S_{1}$ state and internal conversion (IC) to the $S_{0}$ state. ${ }^{11,12}$ The threshold excess energy for $\mathrm{C}_{6} \mathrm{D}_{6}$ was suggested to be significantly smaller than that of $\mathrm{C}_{6} \mathrm{H}_{6}\left(3000 \mathrm{~cm}^{-1}\right){ }^{13}$ This was because that the fluorescence lifetime at the $6^{1} 1^{2}$ level of $\mathrm{C}_{6} \mathrm{D}_{6}$ was appreciably shorter than that at $6^{1} 1^{1}$.

To elucidate the mechanism of this efficient radiationless process, we observed and analyzed the fluorescence and mass-selective resonance enhanced multiphoton ionization (REMPI) excitation spectra of jet-cooled deuterated benzenes. In this article, we present the experimental results and discuss the deuterium effect on the vibronic structure and excited-state dynamics in the $S_{1}$ state of benzene.

\section{EXPERIMENTAL}

The mixture sample of deuterated benzenes is the same as used in Paper I. ${ }^{10}$ In the pure sample measurement, commercial samples of $\mathrm{C}_{6} \mathrm{H}_{6}$ (Wako Chemical, 98\%), $\mathrm{C}_{6} \mathrm{D}_{6}$ (Wako Chemical 99.8\%), and $\mathrm{C}_{6} \mathrm{HD}_{5}$ (Aldrich, 98\%) are also used without additional purification. The vapor was mixed with $\mathrm{He}$ gas (2 atm) and expanded into a vacuum chamber through a pulsed nozzle (automobile fuel injector) to generate a supersonic jet. The fluorescence excitation spectrum was observed using a tunable dye laser (Lambda Physik LPD 3000, $\Delta E=0.1 \mathrm{~cm}^{-1}$, Coumarin 500) pumped by a nanosecond pulsed excimer laser (Coherent Compex Pro 110, $308 \mathrm{~nm}, \Delta t=5 \mathrm{~ns}$ ). The pulsed UV light was obtained with the second harmonics generation of the dye laser output using a BBO crystal. The laser beam was crossed with the supersonic jet at right angles. The distance between the nozzle and the crossing point was $1 \mathrm{~cm}$. Fluorescence from the excited molecules was collected using 
a photomultiplier (Hamamatsu R928). The output was processed using a preamplifier (Stanford Research SR 445A) and a boxcar integrator (Stanford Research SR250). The fluorescence excitation spectrum was obtained by recording the change in the fluorescence intensity with the laser wavelength. Transient fluorescence intensity after the laser pulse was recorded using a storage oscilloscope (LeCroy 9362). The lifetime value was determined by a least-squares fit of the calculated convoluted curve with a single-exponential function.

For the measurement of a mass-selective REMPI excitation spectrum, we used a tunable dye laser (Lambda Physik, Scanmate-OPPO, $\Delta E=0.1 \mathrm{~cm}^{-1}$ ) pumped by a Nd:YAG laser (Spectra Physics, GCR-250-10). The supersonic jet was collimated using a conical skimmer (orifice diameter $3 \mathrm{~mm}$ ) and the cation produced by the REMPI process was detected using a microchannel plate (MCP) detector through a timeof-flight (TOF) tube. We recorded the transient TOF signal by changing the wavelength of the laser light. The mass-selective REMPI excitation spectrum was obtained by extracting the signal intensity during the gated period of a specific ion mass.

\section{RESULTS AND DISCUSSION}

\section{A. The calculation of the effect of deuterium substitution on vibrations}

To assign spectra, the frequencies of normal modes must be known. The $v_{1}$ vibrational energies in the $S_{1}$ state, for example, can be determined by analyzing the fluorescence excitation spectra, but the $v_{6}$ energies cannot be determined because the $0_{0}^{0}$ band is missing for the $S_{1}{ }^{1} B_{2 u} \leftarrow S_{0}{ }^{1} A_{1 g}$ transition. It is, however, possible to estimate them with the assistance of theoretical calculations. Accordingly, we calculated harmonic vibrational energies by TDDFT(B3LYP)/6-31++G(d,p) for the $S_{1}$ state and by DFT(B3LYP)/6-31++G(d,p) for the $S_{0}$ state, using the Gaussian 09 program package. ${ }^{14}$ We then introduced scale factors ( 0.983 for $e_{2 g}$ vibrations and 0.963 for other vibrations) to reproduce the experimental values of $\mathrm{C}_{6} \mathrm{H}_{6}$ and $\mathrm{C}_{6} \mathrm{D}_{6}$, which were determined by analyzing hot bands. ${ }^{7}$ Here, the normal mode $i$ is represented according to Wilson's numbering, ${ }^{15}$ and those of $\mathrm{C}_{6} \mathrm{H}_{6}$ are written as $Q_{i}^{\mathrm{H}}$.

The resultant $v_{1}$ and $v_{6}$ energies and the $0_{0}^{0}$ band transition energies are listed in Table I for the all isotopomers. The $0_{0}^{0}$ band is the transition between the zero-point levels of the $S_{0}$ and $S_{1}$ states. The difference in zero-point energies between two electronic states increases with the number of $\mathrm{D}$ atoms $\left(\mathrm{N}_{\mathrm{D}}\right)$ or with molecular weight, and is independent of the isotopomer structure. Thus, we determined the transition energies of $0_{0}^{0}$ by mass scaling using the observed energies of $\mathrm{C}_{6} \mathrm{H}_{6}$ and $\mathrm{C}_{6} \mathrm{D}_{6}{ }^{16}$ Those energies are used in the analysis of observed spectra. We will discuss the validity of those values in Sec. III B 2. The $v_{6}\left(e_{2 g}\right)$ mode consists mainly of ring deformation. Thus, the vibrational energy does not vary much by the deuterium substitution, although it splits into $v_{6 a}$ and $v_{6 \mathrm{~b}}$ for several isotopomers of lower symmetry. ${ }^{17}$ The $v_{1}\left(a_{1 g}\right)$ mode consists mainly of $\mathrm{C}-\mathrm{C}$ stretching (all in-phase, which is called breathing). Deuteration reduces the vibrational energy of $v_{1}$ more than that of $v_{6}$, and the decrease is approximately proportional to $\mathrm{N}_{\mathrm{D}}$.

Not only the vibrational energies but also the normal coordinates are influenced by deuterium substitution. Both $\mathrm{C}_{6} \mathrm{H}_{6}$ and $\mathrm{C}_{6} \mathrm{D}_{6}$ have $D_{6 h}$ symmetry, but their normal coordinates are slightly different. For example, $Q_{6}\left(e_{2 g}\right)$ of $\mathrm{C}_{6} \mathrm{D}_{6}$ appreciably mixes with $Q_{9}^{\mathrm{H}}$ and $Q_{7}^{\mathrm{H}} \cdot{ }^{18}$ This leads to a change in the normal coordinates and the value of the Coriolis parameter $\zeta_{6}{ }^{17}$ The C-D stretching mode $Q_{2}$ of $\mathrm{C}_{6} \mathrm{D}_{6}$ also mixes with $Q_{1}^{\mathrm{H}}$, the $\mathrm{C}-\mathrm{C}$ stretching mode. ${ }^{19}$

$1,3,5-\mathrm{C}_{6} \mathrm{H}_{3} \mathrm{D}_{3}$ is the only $D_{3 h}$ isotopomer. The $\mathrm{C}-\mathrm{C}$ bending mode $Q_{12}\left(b_{1 u}\right.$ in $\left.D_{6 h}\right)$ has three-fold symmetry. By reduction of molecular symmetry, it becomes the total symmetric $a_{1}^{\prime}$ mode, and it mixes with $Q_{1}$ at approximately $1: 1{ }^{18}$ Thus, the $D_{6 h}$ forbidden $v_{12}$ progressions will probably appear in the vibronic spectrum of $1,3,5-\mathrm{C}_{6} \mathrm{H}_{3} \mathrm{D}_{3}$.

TABLE I. Calculated and observed vibrational energies $\left(\mathrm{cm}^{-1}\right)$ of the $v_{1}$ and $v_{6}$ and calculated energies of $0_{0}^{0}$ in deuterated benzene isotopomers in the $S_{1}$ state.

\begin{tabular}{|c|c|c|c|c|c|c|c|}
\hline \multirow[b]{2}{*}{ Isotopomer } & \multicolumn{2}{|l|}{$v_{1}$} & \multicolumn{2}{|l|}{$v_{6 \mathrm{a}}$} & \multicolumn{2}{|l|}{$v_{6 \mathrm{~b}}$} & \multirow[b]{2}{*}{$0_{0}^{0 \mathrm{~d}}$} \\
\hline & Observation $^{\mathrm{a}}$ & Calc. ${ }^{b}$ & Observation $^{17}$ & Calc. ${ }^{c}$ & Observation $^{17}$ & Calc. $^{\mathrm{c}}$ & \\
\hline $\mathrm{C}_{6} \mathrm{H}_{6}$ & 924 & 922 & 520 & 520 & & & 38086 \\
\hline $\mathrm{C}_{6} \mathrm{H}_{5} \mathrm{D}$ & 920 & 911 & 514 & 515 & 517 & 518 & 38120 \\
\hline$o-\mathrm{C}_{6} \mathrm{H}_{4} \mathrm{D}_{2}$ & $903-912$ & 906 & 513 & 514 & 510 & 511 & 38154 \\
\hline$m-\mathrm{C}_{6} \mathrm{H}_{4} \mathrm{D}_{2}$ & & 904 & 513 & 514 & 510 & 511 & \\
\hline$p-\mathrm{C}_{6} \mathrm{H}_{4} \mathrm{D}_{2}$ & & 908 & 509 & 509 & 515 & 516 & \\
\hline $1,3,5-\mathrm{C}_{6} \mathrm{H}_{3} \mathrm{D}_{3}$ & $890-910$ & 892 & 508 & 509 & & & 38188 \\
\hline $1,2,3-\mathrm{C}_{6} \mathrm{H}_{3} \mathrm{D}_{3}$ & & 899 & 507 & 508 & 507 & 508 & \\
\hline $1,2,4-\mathrm{C}_{6} \mathrm{H}_{3} \mathrm{D}_{3}$ & & 900 & 506 & 506 & 510 & 511 & \\
\hline$o-\mathrm{C}_{6} \mathrm{H}_{2} \mathrm{D}_{4}$ & $885-903$ & 894 & 503 & 503 & 505 & 506 & 38221 \\
\hline$m-\mathrm{C}_{6} \mathrm{H}_{2} \mathrm{D}_{4}$ & & 890 & 503 & 503 & 505 & 507 & \\
\hline$p-\mathrm{C}_{6} \mathrm{H}_{2} \mathrm{D}_{4}$ & & 894 & 507 & 508 & 502 & 502 & \\
\hline $\mathrm{C}_{6} \mathrm{HD}_{5}$ & 883 & 886 & 502 & 503 & 497 & 500 & 38255 \\
\hline $\mathrm{C}_{6} \mathrm{D}_{6}$ & 880 & 880 & 497 & 498 & & & 38289 \\
\hline
\end{tabular}

${ }^{a}$ Calculated harmonically from the observed $6_{0}^{1} 1_{0}^{1}$ band.

${ }^{\mathrm{b}}$ Results of TDDFT(B3LYP)/6-31++G(d,p) are scaled by 0.963 .

${ }^{\mathrm{c}}$ Results of TDDFT(B3LYP)/6-31++G(d,p) are scaled by 0.983 .

${ }^{\mathrm{d}}$ Scaled value with the energy of $0_{0}^{0}$ bands from $\mathrm{C}_{6} \mathrm{H}_{6}$ and $\mathrm{C}_{6} \mathrm{D}_{6} \cdot{ }^{16}$ 
In $\mathrm{C}_{6} \mathrm{H}_{5} \mathrm{D}$ and $\mathrm{C}_{6} \mathrm{HD}_{5}$, asymmetric substitution leads to $C_{2 v}$ molecular symmetry and much mixing of normal coordinates. Two components of an originally degenerate vibration show large splittings in their frequencies and forms. Part of the two molecules' normal coordinates and their frequencies are shown in Figs. 1 and 2. The totally symmetric mode $Q_{1}$ mixes with modes of approximately the same vibrational energies, which are $Q_{18 a}^{\mathrm{H}}\left(e_{1 u}\right.$ in $\left.D_{6 h}\right)$ in $\mathrm{C}_{6} \mathrm{H}_{5} \mathrm{D}$ and $Q_{12}^{\mathrm{H}}$ in $\mathrm{C}_{6} \mathrm{HD}_{5}$, as shown by the vibrational forms.

\section{B. Spectral analysis}

\section{Fluorescence excitation spectra using pure samples}

The fluorescence excitation spectra of the $S_{1}{ }^{1} B_{2 u}$ $\leftarrow S_{0}{ }^{1} A_{1 g}$ transition of $\mathrm{C}_{6} \mathrm{H}_{6}$ and $\mathrm{C}_{6} \mathrm{D}_{6}$ are illustrated in Fig. 3, whose scale is the vibrational excess energy from the $0_{0}^{0}$ transition. In the Hückel approximation, the HOMO and LUMO of benzene in $D_{6 h}$ symmetry are represented by $E_{1 g}$ and $E_{2 u}$, respectively. The HOMO $\rightarrow$ LUMO excited state is represented as

$$
E_{1 g} \otimes E_{2 u}=B_{1 u}+B_{2 u}+E_{1 u} .
$$

The $S_{1}$ state is known to be ${ }^{1} B_{2 u}$. Because the $S_{1}{ }^{1} B_{2 u}$ $\leftarrow S_{0}{ }^{1} A_{1 g}$ transition is forbidden, the $0_{0}^{0}$ band possesses no absorption intensity. The vibronic bands are observed in the

\section{$\mathrm{C}_{6} \mathrm{H}_{5} \mathrm{D}$}
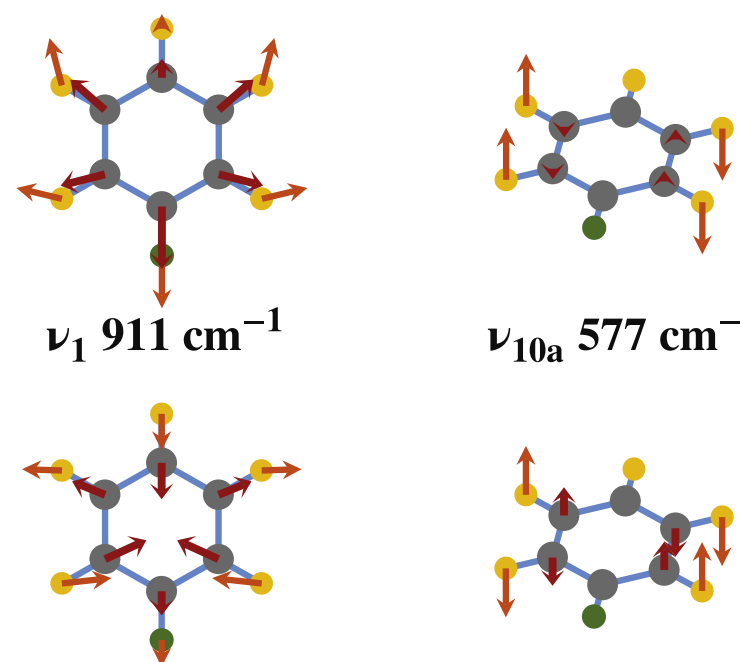

$\nu_{10 \mathrm{a}} 577 \mathrm{~cm}^{-1}$
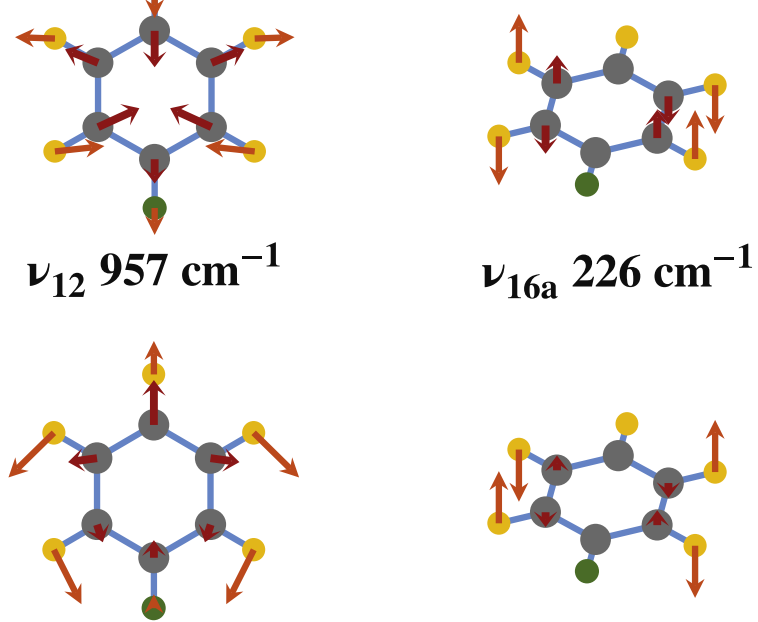

$$
\nu_{18 \mathrm{a}} 931 \mathrm{~cm}^{-1}
$$

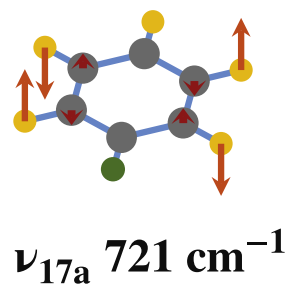

FIG. 1. Part of forms of the $\mathrm{C}_{6} \mathrm{H}_{5} \mathrm{D}$ normal modes. Orange, hydrogen atom; green, deuterium atom.

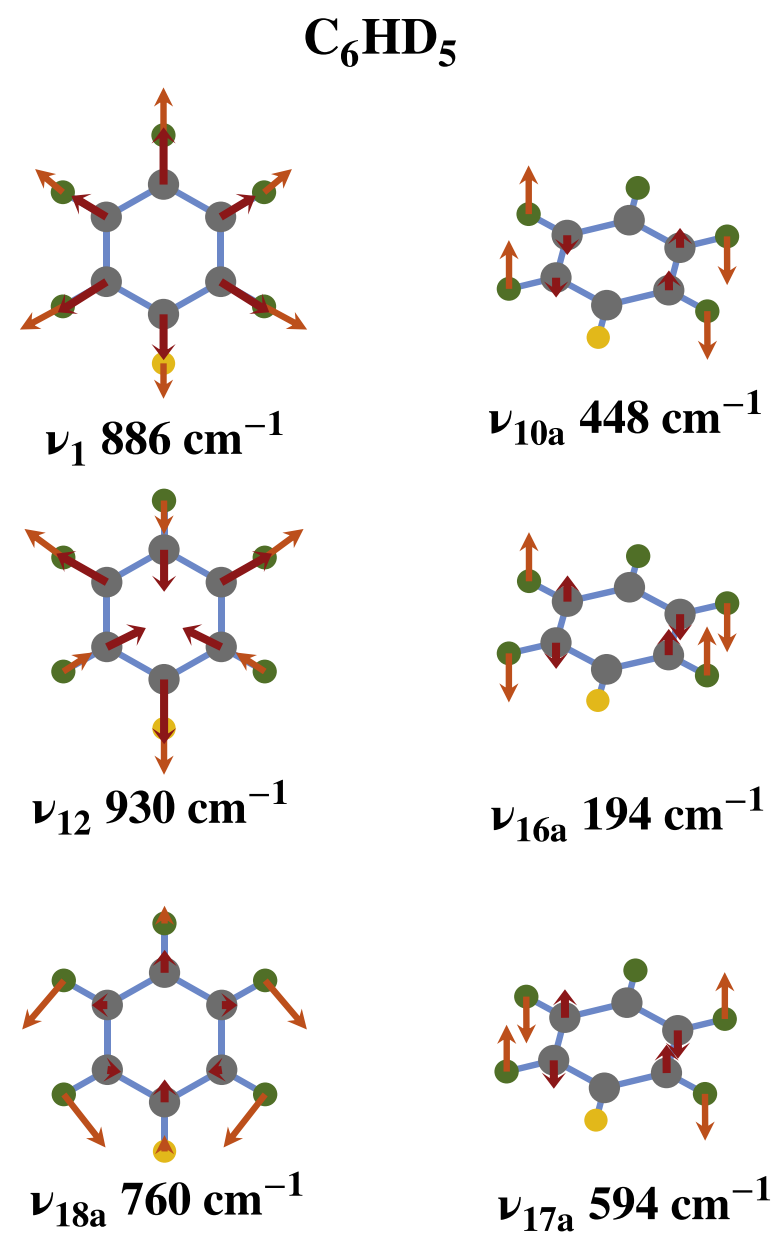

FIG. 2. Part of forms of the $\mathrm{C}_{6} \mathrm{HD}_{5}$ normal modes: Orange, hydrogen atom; green, deuterium atom.

excitation spectrum, which are assigned to the $6_{0}^{1}\left(v_{6}: e_{2 g}\right)$ fundamental band and its combinations with the $v_{1}: a_{1 g}$ vibration. The $E_{1 u}\left(=e_{2 g} \otimes B_{2 u}\right)$ vibronic level of the $S_{1}{ }^{1} B_{2 u}$ electronic state mixes with the $S_{3}{ }^{1} E_{1 u}$ state and borrows absorption intensity from the strong ${ }^{1} E_{1 u}-{ }^{1} A_{1 g}$ transition. The excitation spectrum of jet-cooled $\mathrm{C}_{6} \mathrm{H}_{6}$ consists of three main bands, $6_{0}^{1}, 6_{0}^{1} 1_{0}^{1}$, and $6_{0}^{1} 1_{0}^{2}{ }^{20}$ The spectral features of $\mathrm{C}_{6} \mathrm{D}_{6}$ are similar, but some new bands appear and there is an approximately $200 \mathrm{~cm}^{-1}$ blue-shift of all bands.

These changes in band structure from $\mathrm{C}_{6} \mathrm{H}_{6}$ result from the transformation of normal coordinates caused by deuterium

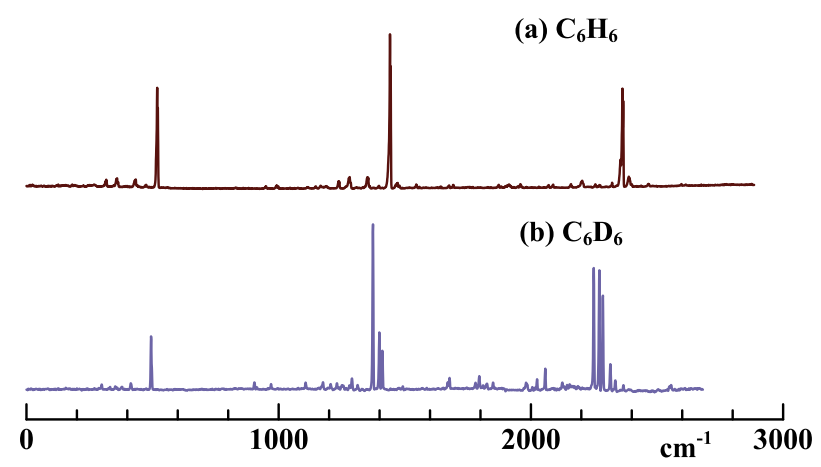

FIG. 3. Fluorescence excitation spectra of $\mathrm{C}_{6} \mathrm{H}_{6}$ and $\mathrm{C}_{6} \mathrm{D}_{6}$. The scale is the vibrational excess energy from the $0_{0}^{0}$ transition. 
substitution, as noted above in Sec. III A. To search this substitution effect, we compared the fluorescence excitation spectrum of pure $\mathrm{C}_{6} \mathrm{HD}_{5}$ to that of $\mathrm{C}_{6} \mathrm{D}_{6}$, which is the molecule differing by only one atom. We assigned the vibronic bands based on the calculated harmonic vibrational energies by TDDFT(B3LYP)/6-31++G(d,p), and the results are shown in Table II. The frequencies of the combination bands are approximated to the summation of the harmonic vibrational energies. Almost all bands are combination bands with $v_{6}$.

The $6^{1}$ vibronic level splits into the $6 \mathrm{a}$ and $6 \mathrm{~b}$ levels for several isotopomers, ${ }^{17}$ but they are not resolved in these spectra because the laser linewidth is $0.1 \mathrm{~cm}^{-1}$ and the rotational envelope is larger than the splitting under the present jet condition (rotational temperature $20 \mathrm{~K}$ ). Their fluorescence excitation spectra around $6_{0}^{1} 1{ }_{0}^{1}$ are shown in the upper panels of Figs. 4(a) and 4(b). The $\mathrm{C}_{6} \mathrm{D}_{6}$ spectrum was already assigned by Rice et al. ${ }^{5}$ Two strong peaks at $25 \mathrm{~cm}^{-1}$ and $37 \mathrm{~cm}^{-1}$ lie on the higher side of $6_{0}^{1} 1_{0}^{1}$ and are characteristic of the spectrum. These both were assigned to $6_{0}^{1} 10_{0}^{2} \cdot v_{10}$ is a nonplanar $e_{1 g}$ vibration, so the vibrational symmetry of $6^{1} 10^{2}$ is represented by

$$
\begin{aligned}
e_{2 g} \otimes e_{1 g} \otimes e_{1 g}= & e_{2 g} \quad\left[6^{1} l^{\mp} 10^{2} l^{0}\right] \\
& +e_{2 g} \quad\left[6^{1} l^{ \pm} 10^{2} l^{ \pm 2}\right] \\
& +\left(a_{1 g}+a_{2 g}\right) \quad\left[6^{1} l^{\mp} 10^{2} l^{ \pm 2}\right] .
\end{aligned}
$$

Of the three components, the vibronic transitions are allowed for the $e_{2 g}$ components by the Herzberg-Teller interaction, and $6_{0}^{1} l^{\mp} 10_{0}^{2} l_{0}^{0}$ is then allowed by the first-order interaction and $6_{0}^{1} l^{ \pm} 10_{0}^{2} l_{0}^{ \pm 2}$ by the third-order interaction. There should be, however, appreciable intensity difference between the two components, although it is not observed in the spectrum in addition to large $12 \mathrm{~cm}^{-1}$ split. Rice et al. suggested that the third-order vibrational $l$-type resonance exists between $6^{1} l^{\mp} 10^{2} l^{0}$ and $6^{1} l^{ \pm} 10^{2} l^{ \pm 2}$. This resonance obeys the selection rule $\Delta l_{6}=\Delta l_{10}= \pm 2$, and the rotationally resolved spectrum of $6_{0}^{1} 10_{0}^{2}$ was resolved based on this resonance. ${ }^{21}$ This interaction allows $6_{0}^{1} l^{\mp} 10_{0}^{2} l_{0}^{0}$ and $6_{0}^{1} l^{ \pm} 10_{0}^{2} l_{0}^{ \pm 2}$ to mix together, which leads to two strong peaks with a large split.

Similarly, in the $\mathrm{C}_{6} \mathrm{HD}_{5}$ spectrum, two strong peaks are observed on the $20 \mathrm{~cm}^{-1}$ and $29 \mathrm{~cm}^{-1}$ higher energy side of the $6_{0}^{1} 1_{0}^{1}$ band. Because of its $C_{2 v}$ molecular symmetry,

\begin{tabular}{|c|c|c|c|}
\hline $\begin{array}{c}\mathrm{C}_{6} \mathrm{D}_{6} \\
\left.\text { Observation(Calc. }{ }^{\mathrm{a}}\right)\end{array}$ & Assignment & $\begin{array}{c}\mathrm{C}_{6} \mathrm{HD}_{5} \\
\text { Observation }\left(\text { Calc. }^{\mathrm{a}}\right)\end{array}$ & Assignment \\
\hline 299(303) & $6_{1}^{0} 1_{0}^{1}$ & $303(304)$ & $6_{1}^{0} 1_{0}^{1}$ \\
\hline $360(355)$ & $6_{0}^{1} 16_{1}^{1}$ & $355(355)$ & $6_{0}^{1} 16_{1}^{1}$ \\
\hline $414(418)$ & $6_{1}^{2}$ & $415(421)$ & $6_{1}^{2}$ \\
\hline 494(495) & $6_{0}^{1}$ & $500(501)$ & $6_{0}^{1}$ \\
\hline 904(886) & $6_{0}^{1} 16_{0}^{2}$ & & \\
\hline $914(886)$ & $6_{0}^{1} 16_{0}^{2}$ & & \\
\hline $1169(1169)$ & $6_{0}^{1} 1_{0}^{1} 10_{1}^{1}$ & 1176(1176) & $6_{0}^{1} 1_{0}^{1} 10_{1}^{1}$ \\
\hline $1176(1183)$ & $6_{1}^{0} 1_{0}^{2}$ & $1185(1188)$ & $6_{1}^{0} 1_{0}^{2}$ \\
\hline \multirow[t]{2}{*}{ 1206(1203) } & $6_{0}^{1} 4_{0}^{1} 10_{0}^{1}$ & $1217(1216)$ & $6_{0}^{1} 4_{0}^{1}(10 a)_{0}^{1}$ \\
\hline & & $1256(1256)$ & $6_{0}^{1} 4_{0}^{1}(10 b)_{0}^{1}$ \\
\hline $1231(1240)$ & $6_{0}^{1} 1_{0}^{1} 16_{1}^{1}$ & $1239(1238)$ & $6_{0}^{1} 1{ }_{0}^{1} 16_{1}^{1}$ \\
\hline $1281(1286)$ & $6_{0}^{1} 16_{0}^{1} 17_{0}^{1}$ & $1295(1294)$ & $6_{0}^{1} 16_{0}^{1}(17 \mathrm{a})_{0}^{1}$ \\
\hline 1291(1294) & $6_{1}^{2} 1_{0}^{1}$ & 1302(1307) & $6_{1}^{2} 1_{0}^{1}$ \\
\hline 1374(1378) & $6_{0}^{1} 1_{0}^{1}$ & 1383(1387) & $6_{0}^{1} 1_{0}^{1}$ \\
\hline 1399(1394) & $6_{0}^{1} 10_{0}^{2}$ & 1403(1397) & $6_{0}^{1}(10 a)_{0}^{2}$ \\
\hline 1411(1394) & $6_{0}^{1} 10_{0}^{2}$ & 1412(1397) & $6_{0}^{1}(10 a)_{0}^{2}$ \\
\hline $1492(1498$ or 1482$)$ & $8_{0}^{1}$ or $6_{0}^{3}$ & $\begin{array}{c}1478(1476 \text { or } 1473) \\
1483(1481)\end{array}$ & $\begin{array}{c}6_{0}^{1}(10 \mathrm{~b})_{0}^{2} \text { or }(8 \mathrm{a})_{0}^{1} \\
(8 \mathrm{~b})_{0}^{1}\end{array}$ \\
\hline $1670(1685)$ & $6_{0}^{1} 17_{0}^{2}$ & $1682(1689)$ & $6_{0}^{1}(17 a)_{0}^{2}$ \\
\hline $1678(1685)$ & $6_{0}^{1} 17_{0}^{2}$ & $1756(1764)$ & $6_{0}^{1}(17 b)_{0}^{2}$ \\
\hline 1781(1766) & $6_{0}^{1} 16_{0}^{2} 1_{0}^{1}$ & & \\
\hline 1795(1766) & $6_{0}^{1} 16_{0}^{2} 1_{0}^{1}$ & & \\
\hline $1826(1815)$ & $60_{0}^{1} 5_{0}^{2}$ & 1889(1897) & $60_{0}^{1} 5_{0}^{2}$ \\
\hline $2125(2120)$ & $6_{0}^{1} 1_{0}^{2} 16_{1}^{1}$ & $2128(2127)$ & $6_{0}^{1} 1_{0}^{2} 16_{1}^{1}$ \\
\hline $2168(2174)$ & $6_{1}^{2} 1_{0}^{2}$ & 2198(2193) & $6_{1}^{2} 1_{0}^{2}$ \\
\hline $2249(2257)$ & $6_{0}^{1} 1_{0}^{2}$ & $2270(2273)$ & $6_{0}^{1} 1_{0}^{2}$ \\
\hline $2272(2279)$ & $6_{0}^{1} 10_{0}^{2} 1_{0}^{1}$ & $2283(2283)$ & $6_{0}^{1}(10 a)_{0}^{2} 1_{0}^{1}$ \\
\hline $2286(2279)$ & $6_{0}^{1} 10_{0}^{2} 1_{0}^{1}$ & $2294(2283)$ & $6_{0}^{1}(10 a)_{0}^{2} 1_{0}^{1}$ \\
\hline \multirow[t]{2}{*}{ 2315(2319) } & $7_{0}^{1}$ & $2316(2324$ or 2323$)$ & $(7 b)_{0}^{1}$ or $6_{0}^{1}(10 a)_{0}^{1}(10 b)_{0}^{1}$ \\
\hline & & $2336(2324$ or 2323$)$ & $(7 b)_{0}^{1}$ or $6_{0}^{1}(10 a)_{0}^{1}(10 b)_{0}^{1}$ \\
\hline $2335(2343)$ & $6_{0}^{1} 12_{0}^{2}$ & $2361(2362$ or 2362$)$ & $6_{0}^{1} 12_{0}^{2}$ or $6_{0}^{1}(10 b)_{0}^{2}$ \\
\hline $2556(2534)$ & $6_{0}^{1} 3_{0}^{2}$ & $2384(2384)$ & $60_{0}^{1} 3_{0}^{2}$ \\
\hline
\end{tabular}

TABLE II. Vibrational energies $\left(\mathrm{cm}^{-1}\right)$ and band assignments observed in the fluorescence excitation spectra of the $S_{1} \leftarrow S_{0}$ transition in $\mathrm{C}_{6} \mathrm{D}_{6}$ and $\mathrm{C}_{6} \mathrm{HD}_{5}$.

${ }^{\mathrm{a} R e s u l t s}$ of TDDFT(B3LYP)/6-31++G(d,p) harmonic calculation are scaled by 0.983 ( $e_{2 g}$ vibration only) and 0.963 (other vibrations) 
(a) $\mathrm{C}_{6} \mathrm{HD}_{5}$

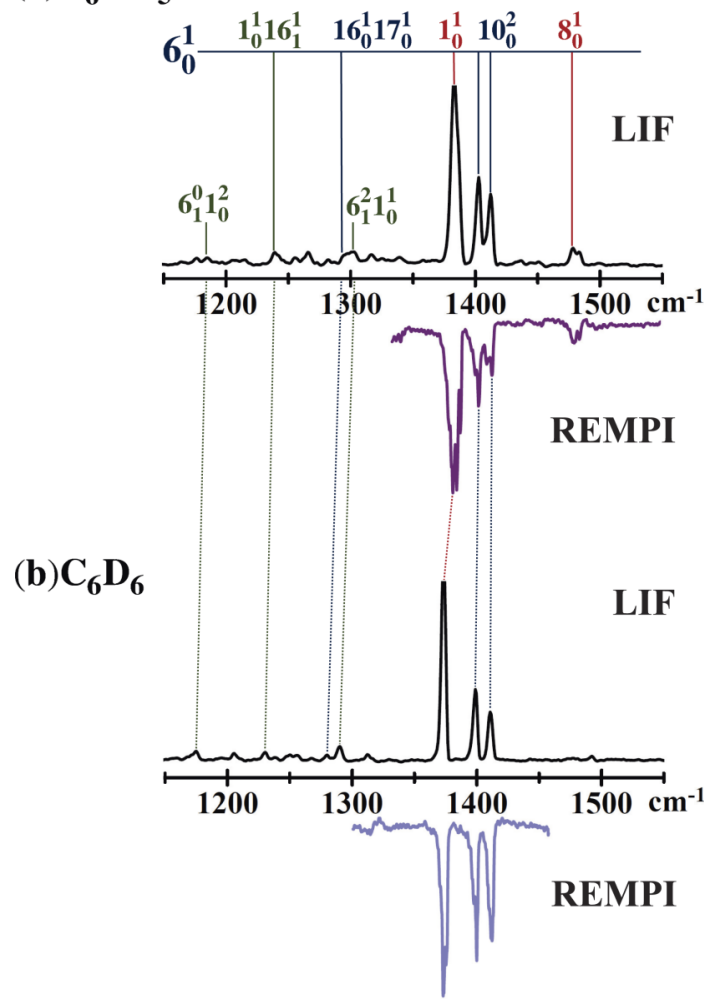

FIG. 4. Fluorescence excitation spectra (upper) and excitation REMPI spectra (lower) of $6_{0}^{1} 1_{0}^{1}$ of (a) $\mathrm{C}_{6} \mathrm{HD}_{5}$ and (b) $\mathrm{C}_{6} \mathrm{D}_{6}$. The scale is the vibrational excess energy from the $0_{0}^{0}$ transition.

the degeneracy of $v_{10}$ is broken into two components, $v_{10 a}\left(a_{2}: 448 \mathrm{~cm}^{-1}\right)$ and $v_{10 b}\left(b_{1}: 487 \mathrm{~cm}^{-1}\right)$. The vibrational energies of the observed peaks correspond to that of $6_{0}^{1}(10 \mathrm{a})_{0}^{2}$. However, it is possible that $v_{10 a}$ and $v_{10 b}$ also mix in $\mathrm{C}_{6} \mathrm{HD}_{5}$ by an interaction that causes the vibrational $l$-type resonance attributed to the vibrational angular momentum along the $c$ axis because of the relatively small effect of mono-hydration on $v_{10}$.

The fluorescence excitation spectra of $\mathrm{C}_{6} \mathrm{HD}_{5}$ and $\mathrm{C}_{6} \mathrm{D}_{6}$ around $6_{0}^{1} 1_{0}^{2}$ are shown in Figs. 5(a) and 5(b), upper panels. In $\mathrm{C}_{6} \mathrm{D}_{6}$, new bands are also observed, in addition to the main bands which are assigned to the $v_{1}$ combination bands with those appearing around $6_{0}^{1} 1_{0}^{1}$. We assigned them to $7_{0}^{1}\left(\nu_{7}: e_{2 g}\right)$, $6_{0}^{1} 12_{0}^{2}$, and $6_{0}^{1} 3_{0}^{2}\left(\nu_{3}: a_{2 g}\right)$, including only in-plane vibrations. In $\mathrm{C}_{6} \mathrm{HD}_{5}$, many vibronic levels are candidates for the observed vibronic bands in this higher energy region because of its lower symmetry. However, the strongest bands could be similarly assigned to $\mathrm{C}_{6} \mathrm{D}_{6}$. The intensity ratio of $6_{0}^{1} 10_{0}^{2} 1_{0}^{1}$ to $6_{0}^{1} 1_{0}^{2}$ is larger than that of $6_{0}^{1} 10_{0}^{2}$ to $6_{0}^{1} 1{ }_{0}^{1}$ in both molecules, indicating extensive mixing between $6^{1} 1^{2}$ and $6^{1} 10^{2} 1^{1}$ levels.

\section{Mass-selective excitation REMPI spectra using the mixture sample}

Through analysis of the pure sample spectra, we were able to assign the observed strong vibronic bands. We then performed additional research on the change of vibronic structure by deuteration using the mixture sample of deuterated benzenes. We observed the fluorescence excitation spectrum, and the results for the $6_{0}^{1}$ band are shown in (a) $\mathrm{C}_{6} \mathrm{HD}_{5}$

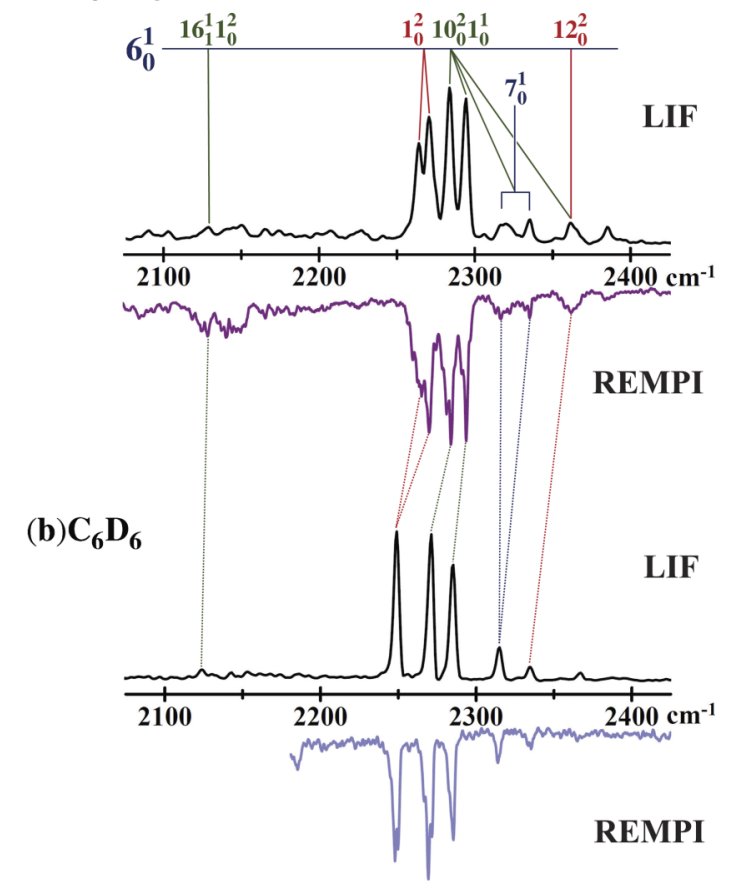

FIG. 5. Fluorescence excitation spectra (upper) and excitation REMPI spectra (lower) of $6_{0}^{1} 1_{0}^{2}$ of (a) $\mathrm{C}_{6} \mathrm{HD}_{5}$ and (b) $\mathrm{C}_{6} \mathrm{D}_{6}$. The scale is the vibrational excess energy from the $0_{0}^{0}$ transition.

Fig. 6(a). The mass-selective REMPI excitation spectra are shown in Fig. 6(b). The transition energy only depends on the molecular mass, which increases by approximately $30 \mathrm{~cm}^{-1}$ as $\mathrm{N}_{\mathrm{D}}$ increases, and is independent of the isotopomer structure. This energy dependence on $\mathrm{N}_{\mathrm{D}}$ is consistent with the result of $0_{0}^{0}$ transition energy calculation (Sec. III A). The vibrational energies of $\mathrm{C}-\mathrm{H}$ stretching and wagging modes are significantly reduced by the deuterium substitution. The total zero-point energy, therefore, becomes smaller as the $N_{D}$ increases. Because this deuterium effect is larger in the $S_{0}$ state, the $0_{0}^{0}$ transition energy increases (blue shift) by the deuterium

(a) LIF $\quad \mathbf{6}_{0}^{1}$

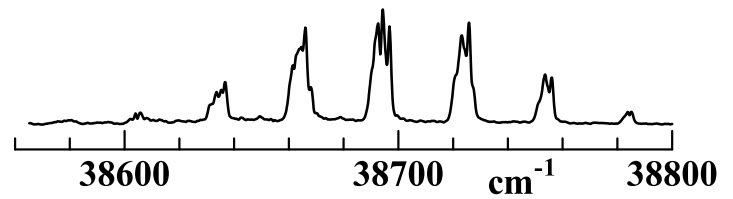

(b) REMPI

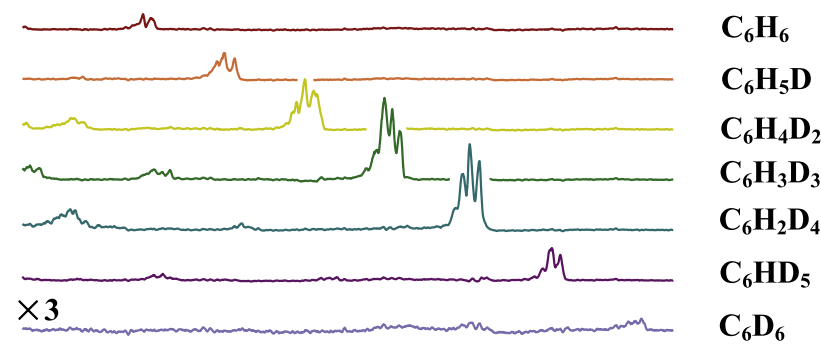

FIG. 6. Fluorescence excitation spectra (a) and excitation REMPI spectra (b) of $6_{0}^{1}$ with the mixture sample. 
substitution. The shift by per-deuteration is known: $203 \mathrm{~cm}^{-1}$ for benzene $\left(\mathrm{C}_{6} \mathrm{H}_{6}\right.$ and $\left.\mathrm{C}_{6} \mathrm{D}_{6}\right),{ }^{7} 118 \mathrm{~cm}^{-1}$ for naphthalene, $\left(\mathrm{C}_{10} \mathrm{H}_{8}\right.$ and $\left.\mathrm{C}_{10} \mathrm{D}_{8}\right),{ }^{22}$ and $69 \mathrm{~cm}^{-1}$ for anthracene $\left(\mathrm{C}_{14} \mathrm{H}_{10}\right.$ and $\left.\mathrm{C}_{14} \mathrm{D}_{10}\right){ }^{23}$ We discovered for the first time that, in the case of partial deuteration, the $0_{0}^{0}$ transition energy increases by approximately $35 \mathrm{~cm}^{-1}$ as $\mathrm{N}_{\mathrm{D}}$ increases. Furthermore, if the $0_{0}^{0}$ band could be observed, its spectral features would be similar to those of the $6_{0}^{1}$ band, since the $v_{6}\left(e_{2 g}\right)$ vibrational energy does not vary much by the deuterium substitution. The area intensity ratio of the $6_{0}^{1}$ bands is approximately $1: 6: 15: 20: 15: 6: 1$, which is the abundance ratio of isotopomers at the statistical limit. The splitting of $6 \mathrm{a}$ and $6 \mathrm{~b}$ is not resolved in the present measurement.

The spectra around the $60_{0}^{1} 1_{0}^{1}$ band are shown in Fig. 7. The splitting with $\mathrm{N}_{\mathrm{D}}$ is smaller (approximately $25 \mathrm{~cm}^{-1}$ ) and the band structure is more unclear than that of $6_{0}^{1}$, because the $v_{1}$ vibrational energies vary depending on $\mathrm{N}_{\mathrm{D}}$. Some new bands also appear in addition to $6_{0}^{1} 1{ }_{0}^{1}$. For $\mathrm{C}_{6} \mathrm{H}_{5} \mathrm{D}$, the mixing between normal coordinates increases by its lower symmetry, as well as $\mathrm{C}_{6} \mathrm{HD}_{5}$. The bands around $6_{0}^{1} 1_{0}^{1}$ are very broad. This indicates that some bands mix strongly with $6_{0}^{1} 1{ }_{0}^{1}$ in $\mathrm{C}_{6} \mathrm{H}_{5} \mathrm{D}$. We assigned these mixed bands as $6_{0}^{1} 16_{0}^{1} 17_{0}^{1}$ and the combination bands with $v_{18 a}$ or $v_{12}$ totally symmetric vibrations, with the assistance of theoretical harmonic calculations. The forms of these vibrations are shown in Fig. 1. It is possible, however, that the $6_{0}^{1} 16_{0}^{1} 17_{0}^{1}$ components could be mixed strongly by an $l$-type resonance as well as in the $6_{0}^{1} 10_{0}^{2}$ level of $\mathrm{C}_{6} \mathrm{D}_{6}$ and $\mathrm{C}_{6} \mathrm{HD}_{5}$. Thus, the perturbation might be strong, disturbing the precise expectation of their band energies and rotational contours. The band assignments for $\mathrm{C}_{6} \mathrm{H}_{4} \mathrm{D}_{2}, \mathrm{C}_{6} \mathrm{H}_{3} \mathrm{D}_{3}$, and $\mathrm{C}_{6} \mathrm{H}_{2} \mathrm{D}_{4}$ are difficult because vibronic bands of each isotopomer are superimposed on the mass-selective REMPI spectrum of each mass number. However, it is expected that $6_{0}^{1} 1_{0}^{1}$ is the main band and that other bands may appear. Fig. 8 shows the expectation of the position of some combination bands with $v_{6}$ using ab initio harmonic calculations. The combination band including $v_{12}$ would be especially strong because it mixes with $v_{1}$.

(a) LIF

$$
6_{0}^{1} 1_{0}^{1}
$$

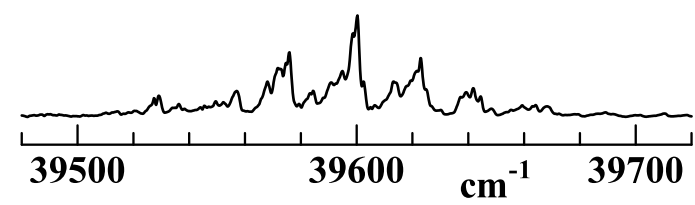

(b) REMPI

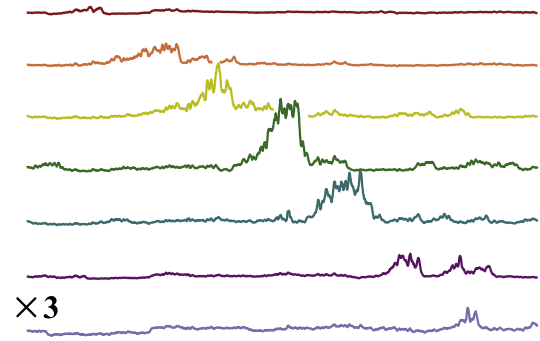

$\mathrm{C}_{6} \mathrm{H}_{6}$

$\mathrm{C}_{6} \mathrm{H}_{5} \mathrm{D}$

$\mathrm{C}_{6} \mathrm{H}_{4} \mathbf{D}_{2}$

$\mathrm{C}_{6} \mathrm{H}_{3} \mathrm{D}_{3}$

$\mathrm{C}_{6} \mathrm{H}_{2} \mathrm{D}_{4}$

$\mathrm{C}_{6} \mathrm{HD}_{5}$

$\mathrm{C}_{6} \mathrm{D}_{6}$

FIG. 7. Fluorescence excitation spectra (a) and excitation REMPI spectra (b) of $6{ }_{0}^{1} 1_{0}^{1}$ with the mixture sample.

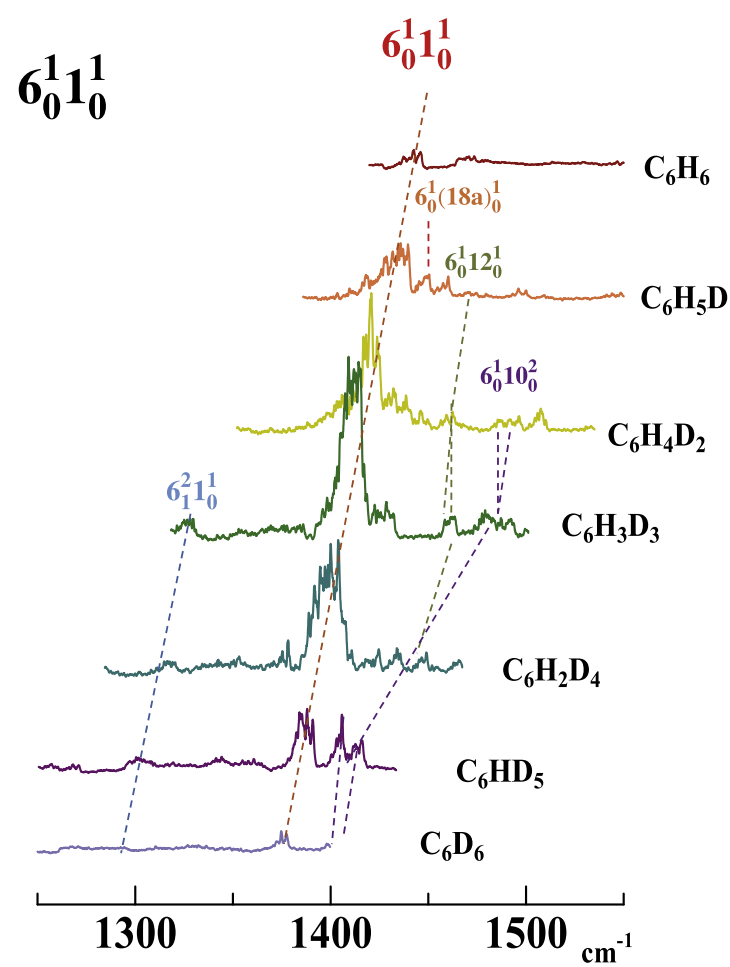

FIG. 8. Excitation REMPI spectra of $60_{0}^{1} 1_{0}^{1}$ and the calculated position of part of the main combination bands. The scale is the vibrational excess energy from the $0_{0}^{0}$ transition.

The spectra of the $6_{0}^{1} 1_{0}^{2}$ band are shown in Fig. 9. The fluorescence excitation spectrum is so complicated that the main bands of $\mathrm{C}_{6} \mathrm{D}_{6}$ and $\mathrm{C}_{6} \mathrm{HD}_{5}$ are unclear, suggesting that some nonradiative relaxing process is enforced and the bands of these molecules are losing intensity. Yet, the results from the mass-selective REMPI spectra and the pure sample spectra show that the complexity of $6_{0}^{1} 1_{0}^{2}$ is a result of the intensity transfer from $6_{0}^{1} 1_{0}^{2}$ to $6_{0}^{1} 10_{0}^{2} 11_{0}^{1}$, not a result of the loss of intensity by a fast electronic relaxation process. For $\mathrm{C}_{6} \mathrm{H}_{5} \mathrm{D}$, the spectrum around $6_{0}^{1} 1_{0}^{2}$ is not different from that around $6_{0}^{1} 1{ }_{0}^{1}$. Thus, we expect that most main bands are combination

(a) LIF

$6_{0}^{1} 1_{0}^{2}$

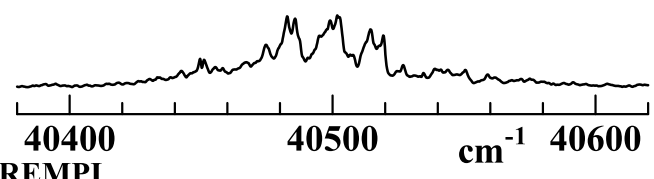

(b) REMPI

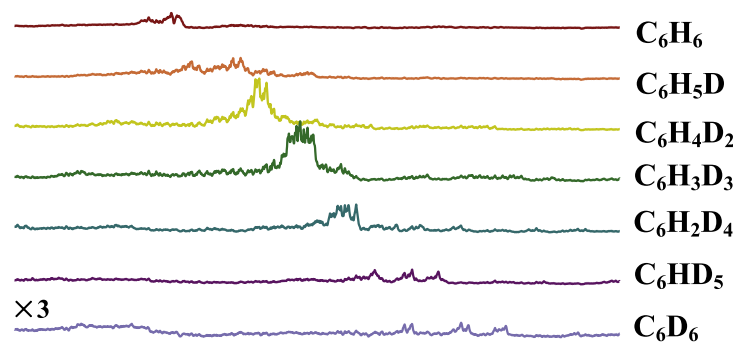

FIG. 9. Fluorescence excitation spectra (a) and excitation REMPI spectra (b) of $6_{0}^{1} 1_{0}^{2}$ with the mixture sample. 
bands between those shown in $6_{0}^{1} 1_{0}^{1}$ and $v_{1}, v_{18 a}$, and $v_{12}$. There are too many allowed vibronic bands to perform a definite assignment, so additional experiments must be conducted; these should include observation of the dispersed fluorescence spectra and high-resolution excitation spectra as well as the intensity calculations for the forbidden transitions. ${ }^{24,25}$

\section{Observed lifetime and nonradiative process}

We observed the fluorescence lifetime for the excitation of a prominent vibronic band using the pure samples or the mixture sample, and the results are shown in Table III. The decay curves of some bands could not be analyzed by singleexponential model, which implies that they have multiple components of different lifetimes. Furthermore, some results are different from those of previous studies. This may be due to the mixing between vibronic levels in addition to the laser resolution. The ultrahigh-resolution spectrum of $\mathrm{C}_{6} \mathrm{H}_{6}$ shows that the lifetime is different with rotational lines, which is caused by interaction with other vibronic levels. ${ }^{26}$ When different rotational lines are excited, therefore, even if they are in the same vibronic band, the resultant lifetimes are different. In the present study, similarly, various lifetimes may be observed for $6^{1} 1^{n}$ and also for the vibronic levels which are mixed with $6^{1} 1^{n}$ by anharmonic interactions such as the Coriolis interaction.

The nonradiative rate increases on $6^{1} 1^{2}$ compared to $6^{1} 1^{1}$, and for $\mathrm{C}_{6} \mathrm{D}_{6}$ and $\mathrm{C}_{6} \mathrm{HD}_{5}$, the lifetimes of $6^{1} 10^{2} 1^{1}$ are shorter than that of $6^{1} 1^{2}$. This means that the observed shortening of the fluorescence lifetime is a result of the increases in mixing between the $6^{1} 1^{2}$ and $6^{1} 10^{2} 1^{1}$ levels via the IVR through vibronic interaction. This coincides with the stronger intensity of $6^{1} 10^{2} 1^{1}$ observed in fluorescence excitation spectra.

Lifetime becomes longer as the $\mathrm{N}_{D}$ increases (the deuterium effect). The exception is the very short $\mathrm{C}_{6} \mathrm{H}_{5} \mathrm{D}$ lifetimes, which are even shorter than those of $\mathrm{C}_{6} \mathrm{H}_{6}$. These bands were observed in the mixture sample, but their short lifetimes have already been reported by Rice et al. ${ }^{6}$ Generally, the larger the molecular mass, the lower the energy at which the increase in the nonradiative relaxation starts, because a heavy molecule has a large vibrational level density. However, this general rule is not true in the present case, and increases in the nonradiative relaxing rate are steeper in $\mathrm{C}_{6} \mathrm{H}_{5} \mathrm{D}$ than in the heaviest isotopomer $\mathrm{C}_{6} \mathrm{D}_{6}$. This result suggests that the IVR nonradiative relaxation is vibration-selective and not within a statistical limit where the relaxation depends only on the level density. Thus, mode-selective lifetimes are also observed in the larger molecule, tetracene. ${ }^{27,28}$ The reason why this fast relaxation rate increases is shown in $\mathrm{C}_{6} \mathrm{H}_{5} \mathrm{D}$, and it may be a result of mixing with $6^{1} 16^{1} 17^{1} 1^{n}$, which has energy almost equal to that of $6^{1} 1^{n}$.

\section{Channel three}

We next examined the deuterium effect on channel three, which is a drastic increase of radiationless transition at the high vibrational levels of the $S_{1}$ state. Channel three threshold is affected by deuterium substitution. Knee et al. argues that for $\mathrm{C}_{6} \mathrm{D}_{6}$, the increase in the IC rate starts at a lower energy than for $\mathrm{C}_{6} \mathrm{H}_{6} \cdot{ }^{13}$ Thus, it is helpful to study the channel three threshold with regard to other deuterated benzene molecules. As shown in Section III C, the mixing of vibronic levels enhances nonradiative IVR relaxation in $6^{1} 1^{2}$. However, no drastic shortening of lifetime associate with channel three was observed in any of the observed spectra in the present study. This coincides with the similarity of intensity distribution between fluorescence excitation spectra and mass-selective REMPI spectra, because a high-intensity discrepancy should appear if channel three occurs. ${ }^{12}$ Thus, in all the isotopomers, the threshold of channel three is in an energy region at least higher than $6^{1} 1^{2}$.

The detailed mechanism of channel three has not been clarified sufficiently. The radiative lifetime of $\mathrm{C}_{6} \mathrm{H}_{6}$ is estimated to be approximately $1000 \mathrm{~ns},{ }^{4,5}$ so that the

TABLE III. Observed lifetimes(ns) of benzene isotopomers. ${ }^{\mathrm{a}, \mathrm{b}}$

\begin{tabular}{|c|c|c|c|c|c|c|c|c|}
\hline \multirow[b]{2}{*}{ Isotopomer } & \multicolumn{2}{|l|}{$6_{0}^{1}$} & \multicolumn{2}{|l|}{$6_{0}^{1} 1_{0}^{1}$} & \multicolumn{2}{|l|}{$6_{0}^{1} 1_{0}^{2}$} & & \\
\hline & Observation & Ref. & Observation & Ref. & Observation & Ref. & & \\
\hline $\mathrm{C}_{6} \mathrm{H}_{6}$ & $56(3)$ & 87 & $53(1)$ & 82 & $36(2)^{\mathrm{c}}$ & 72 & & \\
\hline $\mathrm{C}_{6} \mathrm{H}_{5} \mathrm{D}$ & 61(7) & 88 & $44(4)^{\mathrm{c}}$ & 66 & $18(0)^{\mathrm{c}}$ & 39 & & \\
\hline $\mathrm{C}_{6} \mathrm{H}_{4} \mathrm{D}_{2}$ & $65(8)$ & & $63(3)$ & & $22(3)^{c}$ & & & \\
\hline $\mathrm{C}_{6} \mathrm{H}_{3} \mathrm{D}_{3}$ & $75(12)$ & & $65(4)$ & & $21(4)^{\mathrm{c}}$ & & & \\
\hline $\mathrm{C}_{6} \mathrm{H}_{2} \mathrm{D}_{4}$ & $86(13)$ & & $60(10)$ & & $22(3)^{\mathrm{c}}$ & & & \\
\hline $\mathrm{C}_{6} \mathrm{HD}_{5}$ & $81(7)$ & 123 & $73(1)$ & 92 & $38(3)$ & 51 & & \\
\hline \multirow[t]{2}{*}{$\mathrm{C}_{6} \mathrm{D}_{6}$} & $115(10)$ & 144 & 92(9) & 110 & $70(11)$ & 69 & & \\
\hline & \multicolumn{2}{|c|}{$6_{0}^{1} 10_{0}^{2}($ Low $)$} & \multicolumn{2}{|c|}{$6_{0}^{1} 10_{0}^{2}(\mathrm{High})$} & \multicolumn{2}{|c|}{$6_{0}^{1} 10_{0}^{2} 1_{0}^{1}$ (Low) } & $6_{0}^{1} 10_{0}^{2} 11_{0}^{1}$ & \\
\hline Isotopomer & Observation & Ref. & Observation & Ref. & Observation & Ref. & Observation & Ref. \\
\hline $\mathrm{C}_{6} \mathrm{HD}_{5}$ & $52(1)$ & & $52(1)$ & & $29(7)^{c}$ & & $26(5)^{c}$ & \\
\hline $\mathrm{C}_{6} \mathrm{D}_{6}$ & $65(4)$ & 69 & $69(7)$ & 93 & $52(1)$ & & $47(3)$ & \\
\hline
\end{tabular}

${ }^{\mathrm{a}} \mathrm{C}_{6} \mathrm{H}_{6}, \mathrm{C}_{6} \mathrm{HD}_{5}$, and $\mathrm{C}_{6} \mathrm{D}_{6}$ were observed using the pure samples, and the others were mixture samples.

${ }^{b}$ Values of "Ref." are from Ref. $6\left(\mathrm{C}_{6} \mathrm{H}_{5} \mathrm{D}\right.$ and $\left.\mathrm{C}_{6} \mathrm{HD}_{5}\right)$, Ref. $41\left(\mathrm{C}_{6} \mathrm{H}_{6}\right)$, and Refs. 5 and $21\left(\mathrm{C}_{6} \mathrm{D}_{6}\right)$

${ }^{\mathrm{c}}$ Lifetimes of only the shortest component, if the decay curves could not be analyzed with a single-exponential model. 
nonradiative process is dominant in the $S_{1}$ state. It was shown by ultrahigh-resolution laser spectroscopy that intersystem crossing (ISC) to the triplet state is not effective even at low vibronic levels. ${ }^{26,29,30}$ In particular, channel three is considered to be a combined process of the IVR and IC. By the rotational analysis of $6^{1} 1^{3}$ and $14^{1} 1^{2}$ levels of $\mathrm{C}_{6} \mathrm{H}_{6}$, the IC rate was found to be strongly dependent on the rotational quantum numbers, while the anharmonic Coriolis interaction dominates the IVR process. ${ }^{11,12,31}$ The matrix elements for a symmetric top are given by ${ }^{32}$

(i) parallel Coriolis interaction $(z \| c)$,

$$
\left\langle J, K\left|J_{z}\right| J, K\right\rangle=\hbar K,
$$

(ii) perpendicular Coriolis interaction $(z \perp c)$,

$$
\left\langle J, K\left|J_{x} \pm i J_{y}\right| J, K \pm 1\right\rangle=\hbar[J(J+1)-K(K+1)]^{1 / 2} .
$$

From the theoretical analysis on intensity distribution of the observed rotational transitions, the parallel Coriolis interaction was shown to be superior for low $J$ levels, while the perpendicular Coriolis interaction also becomes active at high $J$ levels. ${ }^{12,31,33,34}$ Consequently, the main IVR channel in jet-cooled benzene is considered to be the parallel Coriolis interaction around the out-of-plane $c$ axis. This interaction leads to mixing between $E_{1 u}$ vibronic levels in the $S_{1}$ states followed by enhancement of IC, which causes drastic shortening of fluorescence lifetimes.

Given all this, what kind of interaction between the electronic excited states enhances IC? The IC rate is given by the vibration-rotation Hamiltonian, ${ }^{35,36}$

$$
\begin{aligned}
W_{I C} \propto & \sum_{i}\left|\left\langle\phi_{\mathrm{S}_{0}}\left|\frac{\partial}{\partial Q_{i}}\right| \phi_{\mathrm{S}_{1}}\right)\right|^{2} \mid\left\langle\chi_{\mathrm{S}_{0}}^{v^{\prime \prime}}\left|\frac{\partial}{\partial Q_{i}}\right| \chi_{\mathrm{S}_{1}}^{v^{\prime}}||^{2} \delta\left(E_{\mathrm{S}_{1}}^{v^{\prime}}-E_{\mathrm{S}_{0}}^{v^{\prime \prime}}\right)\right. \\
\approx & \frac{\left|\left\langle\phi_{\mathrm{S}_{0}}\left(r, Q_{0}\right)\left|\left(\frac{\partial U(r, Q)}{\partial Q_{r}}\right)_{Q_{0}}\right| \phi_{\mathrm{S}_{1}}\left(r, Q_{0}\right)\right\rangle\right|^{2}}{\left(E_{\mathrm{S}_{1}}\left(Q_{0}\right)-E_{\mathrm{S}_{0}}\left(Q_{0}\right)\right)^{2}} \\
& \times\left|\left\langle\chi_{\mathrm{S}_{0}}^{v^{\prime \prime}}\left(Q_{r}\right)\left|\frac{\partial}{\partial Q_{r}}\right| \chi_{\mathrm{S}_{1}}^{v^{\prime}}\left(Q_{r}\right)\right\rangle \prod_{j \neq r}\left\langle\chi_{\mathrm{S}_{0}}^{v^{\prime \prime}}\left(Q_{j}\right) \mid \chi_{\mathrm{S}_{1}}^{v^{\prime}}\left(Q_{j}\right)\right\rangle\right|^{2} \\
& \times \delta\left(E_{\mathrm{S}_{1}}^{v^{\prime}}-E_{\mathrm{S}_{0}}^{v^{\prime \prime}}\right) .
\end{aligned}
$$

The first factor is the electronic factor representing the overlap between electronic states by promoting mode $r$. The second factor is the nonadiabatic Franck-Condon factor of the promoting mode $r$, and the third factor is the Franck-Condon factor of the other modes. Considering Eq. (4), there is a vibration which enhances IC.

The importance of out-of-plane vibration was indicated by the theoretical calculations. For example, the conical intersection was found to be between the $S_{0}$ and $S_{1}$ states along the displacement coordinate of the out-of-plane ring deformation, which is consistent with isomerization into prefulvene. ${ }^{37,38}$ However, this contribution is considered to be minor because the efficiency of the isomerization reaction is low in the channel three region. It should be also noted that the mixing of out-of-plane vibrations is small for the $6^{1}$, $6^{1} 1^{1}$, and $6^{1} 1^{2}$ levels because the inertial defect value is very small. ${ }^{26}$ The absolute value of the inertial defect becomes large when the planar molecule is distorted out-of-plane or when the out-of-plane vibrational modes are considerably mixed with the in-plane vibronic level. ${ }^{39,40}$

Although it is difficult to determine the promoting mode $r$, its symmetry is limited because the electronic factor of Eq. (4) must have a non-zero value. The symmetry of $\phi_{S_{0}}$ is $A_{1 g}$ and $\phi_{S_{1}}$ is $B_{2 u}$, so the symmetry of $Q_{r}$ should be $b_{2 u}$ in the direct IC between $S_{1}$ and $S_{0}$. If the indirect IC between $S_{3}-S_{0}$ is possible - the $S_{1}$ state mixes with the $S_{3}{ }^{1} E_{1 u}$ state to some extent - the symmetry of $Q_{r}$ may also be $e_{1 u}$. This indirect IC energy gap is large but it is not impossible. In either cases, the key to IC is in-plane vibration rather than out-of-plane vibration.

\section{CONCLUSIONS}

Using the pure samples of $\mathrm{C}_{6} \mathrm{D}_{6}$ and $\mathrm{C}_{6} \mathrm{HD}_{5}$, we observed and assigned the fluorescence excitation spectra. In the two molecules, there are strong peaks of vibronic bands including out-of-plane vibrations, in addition to $6_{0}^{1} 1_{0}^{n}$.

Using the mixture sample of deuterated benzenes, we observed the fluorescence and REMPI excitation spectra and the fluorescence lifetime for the $6_{0}^{1}, 6_{0}^{1} 1_{0}^{1}$, and $6_{0}^{1} 1_{0}^{2}$ bands of the $S_{1}-S_{0}$ transition. The transition energies of the observed vibronic bands were found to be dependent on only the number of the $\mathrm{D}$ atoms $\left(\mathrm{N}_{\mathrm{D}}\right)$ or the mass number of the deuterated benzene molecules. In the $6^{1} 1^{2}$ level of $\mathrm{C}_{6} \mathrm{D}_{6}$ and $\mathrm{C}_{6} \mathrm{HD}_{5}$, IVR is enhanced to some extent. The lifetime of $\mathrm{C}_{6} \mathrm{H}_{5} \mathrm{D}$ is the shortest among the isotopomers, which means that the nonradiative relaxation process depends on the structure of isotopomers as well as on $\mathrm{N}_{\mathrm{D}}$.

The drastic enhancement of nonradiative decay above $3000 \mathrm{~cm}^{-1}$ in the $S_{1}$ state of benzene is called channel three. This phenomenon is not observed in the present experiment, although lifetimes are somewhat shortened. This means that channel three happens in a much higher region and that the threshold excess energy is not varied much by the deuterium substitution. Channel three is a combined process of IVR caused by parallel Coriolis interaction and IC mainly through the in-plane promoting mode; accordingly, we suggest that the key vibration in this process should be in-plane. However, the mixing of $E_{1 u}$ vibronic levels, including out-of-plane vibrations, is also important for spectral features and decay enhancement. In addition, some researchers have argued that out-of-plane vibrations were important in the IC process as accepting modes. ${ }^{34}$ Thus, high-resolution studies on the vibronic levels, dispersion fluorescence spectra of deuterated benzenes, and the intensity calculations of vibronic spectra are desired to accurately elucidate the excited-state dynamics in the $S_{1}$ state of the deuterated benzene molecules, as well as those in the channel three region such as $6^{1} 1^{3}$ and $14^{1} 1^{2}$.

\section{ACKNOWLEDGMENTS}

This work was partly supported by the Nanotechnology Platform Program (Molecule and Material Synthesis) of the Ministry of Education, Culture, Science and Technology (MEXT), Japan. The experiments were supported by the Inter-University Network for Efficient Utilization of Chemical Research Equipments. 
${ }^{1}$ C. S. Parmenter, Adv. Chem. Phys. 22, 365 (1972).

${ }^{2}$ P. Avouris, W. M. Gelbart, and M. A. El-Sayed, Chem. Rev. 77, 793 (1977).

${ }^{3}$ H. J. Neusser and R. Neuhauser, Adv. Chem. Phys. 101, 409 (1997).

${ }^{4}$ K. G. Spears and S. A. Rice, J. Chem. Phys. 55, 5561 (1971).

${ }^{5}$ A. S. Abramson, K. G. Spears, and S. A. Rice, J. Chem. Phys. 56, 2291 (1972).

${ }^{6}$ C. Guttman and S. A. Rice, J. Chem. Phys. 61, 651 (1974).

${ }^{7}$ J. H. Callomon, T. M. Dunn, and I. M. Mills, Philos. Trans. R. Soc., A 259, 499 (1966).

${ }^{8}$ J. H. Callomon, J. E. Parkin, and R. Lopez-Delgado, Chem. Phys. Lett. 13, 125 (1972).

${ }^{9}$ K. Aron, C. Otis, R. E. Demaray, and P. M. Johnson, J. Chem. Phys. 73, 4167 (1980).

${ }^{10}$ S. Kunishige, T. Katori, M. Baba, M. Nakajima, and Y. Endo, J. Chem. Phys. 143, 244302 (2015).

${ }^{11}$ E. Riedle and H. J. Neusser, J. Chem. Phys. 80, 4686 (1984).

${ }^{12}$ E. Riedle, Th. Weber, U. Schubert, H. J. Neusser, and E. W. Schlag, J. Chem. Phys. 93, 967 (1990).

${ }^{13}$ J. L. Knee, C. Otis, and P. M. Johnson, J. Chem. Phys. 81, 4455 (1984).

${ }^{14}$ M. J. Frisch, G. W. Trucks, H. B. Schlegel, G. E. Scuseria, M. A. Robb, J. R. Cheeseman, G. Scalmani, V. Barone, B. Mennucci, G. A. Petersson, H. Nakatsuji, M. Caricato, X. Li, H. P. Hratchian, A. F. Izmaylov, J. Bloino, G. Zheng, J. L. Sonnenberg, M. Hada, M. Ehara, K. Toyota, R. Fukuda, J. Hasegawa, M. Ishida, T. Nakajima, Y. Honda, O. Kitao, H. Nakai, T. Vreven, J. A. Montgomery, Jr., J. E. Peralta, F. Ogliaro, M. Bearpark, J. J. Heyd, E. Brothers, K. N. Kudin, V. N. Staroverov, T. Keith, R. Kobayashi, J. Normand, K. Raghavachari, A. Rendell, J. C. Burant, S. S. Iyengar, J. Tomasi, M. Cossi, N. Rega, J. M. Millam, M. Klene, J. E. Knox, J. B. Cross, V. Bakken, C. Adamo, J. Jaramillo, R. Gomperts, R. E. Stratmann, O. Yazyev, A. J. Austin, R. Cammi, C. Pomelli, J. W. Ochterski, R. L. Martin, K. Morokuma, V. G. Zakrzewski, G. A. Voth, P. Salvador, J. J. Dannenberg, S. Dapprich, A. D. Daniels, O. Farkas, J. B. Foresman, J. V. Ortiz, J. Cioslowski, and D. J. Fox, GaUssian 09, Revision C.01, Gaussian, Inc., Wallingford, CT, 2010.

${ }^{15}$ E. B. Wilson, Jr., Phys. Rev. 45, 706 (1934).

${ }^{16}$ H. Katô, M. Baba, and S. Kasahara, Bull. Chem. Soc. Jpn. 80, 456 (2007).

${ }^{17}$ S. Kunishige, T. Katori, M. Baba, M. Hayashi, H. Hasegawa, and Y. Ohshima, J. Chem. Phys. 143, 244303 (2015).
${ }^{18}$ K. Krogh-Jespersen, R. P. Rava, and L. Goodman, J. Phys. Chem. 88, 5503 (1984).

${ }^{19}$ Y. Nibu and L. Goodman, Chem. Phys. Lett. 129, 36 (1986).

${ }^{20}$ T. Suzuki and M. Ito, J. Chem. Phys. 91, 4564 (1989).

${ }^{21}$ R. L. Rosman, A. A. Villaeys, K. F. Freed, and S. A. Rice, J. Chem. Phys. 86, 2576 (1987).

${ }^{22}$ S. M. Beck, D. E. Powers, J. B. Hoppkins, and R. E. Smalley, J. Chem. Phys. 73, 2019 (1980).

${ }^{23}$ M. Baba, M. Saitoh, K. Taguma, K. Shinohara, K. Yoshida, Y. Semba, S. Kasahara, N. Nakayama, H. Goto, T. Ishimoto, and U. Nagashima, J. Chem. Phys. 130, 134315 (2009).

${ }^{24}$ H. Xu, P. M. Johnson, and T. J. Sears, J. Chem. Phys. 125, 164331 (2006).

${ }^{25}$ G. V. Lopez, C.-H. Chang, P. M. Johnson, G. E. Hall, T. J. Sears, B. Markiewicz, M. Milan, and A. Teslja, J. Phys. Chem. A 116, 6750 (2012).

${ }^{26}$ A. Doi, S. Kasahara, H. Katô, and M. Baba, J. Chem. Phys. 120, 6439 (2004).

${ }^{27}$ A. Amirav, U. Even, and J. Jortner, J. Chem. Phys. 75, 3770 (1981).

${ }^{28}$ M. Baba, T. Katori, M. Kawabata, S. Kunishige, and T. Yamanaka, J. Phys. Chem. A 117, 13524 (2013).

${ }^{29}$ M. Misono, J. Wang, M. Ushino, M. Okubo, H. Katô, M. Baba, and S. Nagakura, J. Chem. Phys. 116, 162 (2001).

${ }^{30}$ M. Baba, J. Phys. Chem. A 115, 9514 (2011).

${ }^{31}$ D. Y. Baek, J. H. Chen, J. Wang, A. Doi, S. Kasahara, M. Baba, and H. Katô, Bull. Chem. Soc. Jpn. 79, 75 (2006).

${ }^{32}$ I. M. Mills, Pure Appl. Chem. 11, 325 (1965).

${ }^{33}$ A. Helman and R. A. Marcus, J. Chem. Phys. 99, 5002 (1993).

${ }^{34}$ A. Helman and R. A. Marcus, J. Chem. Phys. 99, 5011 (1993).

${ }^{35}$ W. Siebrand, J. Chem. Phys. 46, 440 (1967).

${ }^{36}$ S. H. Lin, J. Chem. Phys. 44, 3759 (1966).

${ }^{37}$ S. Kato, J. Chem. Phys. 88, 3045 (1988).

${ }^{38}$ M. Wanko, M. Garavelli, F. Bernardi, T. A. Niehaus, T. Frauenheim, and M. Elstner, J. Chem. Phys. 120, 1674 (2004).

${ }^{39}$ T. Oka and Y. Morino, J. Mol. Spectrosc. 6, 472 (1961).

${ }^{40}$ T. Oka, J. Mol. Struct. 352-353, 225 (1995).

${ }^{41}$ T. A. Stephenson, P. L. Radloff, and S. A. Rice, J. Chem. Phys. 81, 1060 (1984). 